\title{
Concepções de gênero de homens usuários e profissionais de saúde de serviços de atenção primária e os possíveis impactos na saúde da população masculina, São Paulo, Brasil
}

\author{
M ale users' and primary care services health professionals' \\ conceptions of gender and possible impacts on men's health, \\ São Paulo, Brazil
}

Wagner dos Santos Figueiredo ${ }^{1}$

LiliaBlima Schraiber ${ }^{2}$

\footnotetext{
${ }^{1}$ Departamento deM edicina , Centro de Ciências Biológicas eda Saúde, UniversidadeFederal deSão Carlos. Rodovia Washington Luis Km 235. 13565-905 São Carlos SP. wagfig1@gmail.com

${ }^{2}$ Departamento deM edicina Preventiva, Faculdade de M edicina, Universidade de São Paulo.
}

\begin{abstract}
This paper studied the relation between the exercise of masculinities and health care of men in primary health care services. It focuses on representations and meanings of primary health care service users and professional of what it is to be a man. $M$ ale service users and professionals were interviewed in two primary health care facilities. Diversemodels of masculinity werefound, defining various forms of reasoning upon men's health care. This study indicates that issues such as work, sexuality, body structure, relationship with women, and transformations in gender re lationsareimportant for men, and should beconsidered in health care services.
\end{abstract}

Key words Gender and health, M en's health, Primary health care
Resumo Estudou-se a relação do exercício das masculinidades com o cuidado em saúde para homens na atenção primária, por meio de representações e significados de usuários e trabalhadores acerca do que vem ser homem. Foram entrevistados homens usuários e profissionais de saúde de dois serviços de atenção primária. Encontrou-se uma diversidade demodel os demasculinidadeque podem definir diferentes formas para pensar o cuidado de saúde dos homens. 0 bservou-sequequestões como trabalho, sexualidade, estrutura corporal, relações com as mulheres e transformações nas rel ações de gênero são temasimportantes para os homens e devem ser consideradas nos serviços de saúde.

Palavras-chave Gênero e saúde, Saúde do homem, Atenção primária à saúde 


\section{Introdução}

Em tempos mais recentes, vários estudos vêm discutindo a questão da saúde masculina, buscando compreender as diferentes motivações para os altos perfis de morbimortalidade doshomen ${ }^{1-}$ 3. Parte desses estudos toma como referência a perspectiva de gênero para a reflexão das condições de saúde masculina. Alguns autores associam essas elevadas taxas ao processo de socialização dos homens, no qual poder, força e sucesso, considerados atributos característicos dos homens, resultam em comportamentos que predispõem a doenças e mortes ${ }^{1,4}$. Outros autores apontam que, nesse processo, o cuidado com a saúde não é valorizado como uma questão importante nas vivências masculinas ${ }^{5}$.

Dessa forma, os homens reprimem suas necessidades de saúde e têm dificuldades para expressá-las, procurando menos que as mulheres os serviços de saúde. $\mathrm{Na}$ atenção primária, essa situação torna-se mais emblemática, pois os serviços são destinados principalmente às mulheres, às crianças e aos idosos ${ }^{6,7}$. Os homens consideram o ambiente das unidades básicas de saúde feminilizados, o que provoca neles a sensação de não pertencimento àquele espaço ${ }^{6}$. Da parte dos serviços, estudos mostram que o sistema de cuidados constrói um comportamento de saúde dentro da referência dominante de atribuições degênero, levando à invisibilidade doshomens ${ }^{8,9}$. Com isso, os serviços de atenção primária apresentam dificuldades para acionar práticas de prevenção e promoção da saúde dos homens.

Nesse sentido, a categoria gênero pode contribuir para um alcance maior na compreensão das questões relacionadas à saúde masculina. Gênero é compreendido como uma construção social da diferença sexual etem um sentido relacional, envolvendo homens e mulheres ${ }^{10}$ e constróise em cima devalores que remontam às vivências na vida cotidiana. Por meio desses valores, homens e mulheres adotam determinados comportamentos e atitudes que entendem ser mais condizentes com o esperado socialmente acerca do que venha a ser um homem ou uma mulher.

Por sua vez, a masculinidade é uma configuração prática em torno da posição dos homens nas relações de gênero ${ }^{4,11}$, existindo uma masculinidade culturalmente hegemônica que serve de modelo e é construída nas relações de homens e de mulheres. M as nem todos os homens assumem o modelo como sendo o seu, o que indica a coexistência de inúmeras manifestações de masculinidades, envolvendo aspectos tais como viri- lidade, agressividade, ambição, competitividade, coragem, autoridade, etc.

No campo da saúde, os estudos de gênero têm sido utilizados principalmente quando se discute a saúde da mulher, como demonstra Aquino ${ }^{12}$. Segundo a autora, os trabalhos que tematizam a masculinidadee sua interseção com a saúde só começam a ganhar destaque a partir do final da década de noventa, impulsionados pela expansão da epidemia de aids.

Considerando os altos níveis de morbimortalidade masculina e assumindo que os referenciais de gênero podem contribuir para melhor entender os processos de adoecimento e morte dessa população, este trabal ho tem o objetivo de discutir as representações que usuários e trabal hadores de serviços de atenção primária à saúde revelam acerca do que vem a ser homem. Desse modo, esperamos fornecer maiores subsídios para se investir em ações de promoção, prevenção e assistência à saúde direcionadas aos homens.

\section{Metodologia}

Este trabalho é parte de uma pesquisa maior que estudou as relações entremasculinidades esaúde para compreender como são articuladas a noção de cuidado de saúde com a identidade masculina (ser homem) ${ }^{13}$. A pesquisa investigou como se dão as representaçõ̃es e interações entre usuários (homens) e profissionais de saúde de serviços de atenção primária. A metodologia teve base qualitativa, utilizando duas técnicas de pesquisa: (1) a observação direta dos diferentes contextos, das situações e atividades assistenciais que compõem a prática cotidiana de um serviço de atenção primária e (2) entrevistas semi-estruturadas com diferentes profissionais ehomensusuários. Aqui, discutiremos as representações de gênero apresentadas por esses sujeitos nas entrevistas.

Como se tratava de tema pouco explorado em serviços de atenção básica, escolhemos serviços que tivessem entre suas prioridades a pesquisa e o desenvolvimento de tecnologias inovadoras em atenção primária. Acreditávamos queserviços com essa natureza trariam contribuições valiosas à discussão da problemática da saúde masculina na perspectiva de gênero. Assim, o estudo foi realizado em dois serviços de atenção primária que fazem parte de instituições universitárias da cidade de São Paulo.

Foram selecionados para a pesquisa usuários do sexo masculino de dezoito a sessenta anos e diferentes profissionais que prestam assistência 
nos dois centros de saúde. A seleção de usuários dessa faixa etária justificava-se porque para adolescentes e idosos há estudos e ações específicas. Quanto aos profissionais, optamos por abranger ambos os sexos, com formação universitária edenível médio, ampliando, dessa forma, as repre sentações acerca de gênero. Um outro critério de seleção foi entrevistar os sujeitosquetiveram consultas ou atividades profissionais observadas. 0 roteiro tinha três blocos temáticos: (1) as concepções sobre saúde, corpo, cuidado de si e de outros; (2) as concepções de gênero e (3) as relações entre ser homem e cuidados e problemas de saúde. Aqui discutiremos apenas as questões arroladas no bloco acerca das concepções de gênero.

Entrevistamos 26 usuários e 27 profissionais de saúde. 0 número de entrevistados foi considerado suficiente quando percebemos a reincidência das informações e que essas permitiam uma discussão aprofundada das questões da pesquisa. Os usuários tinham entre 21 e 59 anos ea maior parteera casada ou vivia conjugalmente. Entre as atividades profissionais exercidas, destacam-seos mecânicos, os biscateiros eos que se encontravam afastados do trabalho. Os profissionais tinham entre 29 e 65 anos, sendo apenas sete homens. Quanto à categoria profissional, a maior parte era de médicos e técnicos de enfermagem. 0 tempo de trabalho na instituição variou de um ano até vinte cinco anos.

Seguindo os preceitos da ética em pesquisa, todas as entrevistas foram precedidas de consentimento. Para garantir o caráter sigiloso das informações, todos os depoentes foram codificados com nomes fictícios. A interpretação foi feita segundo a técnica de análise temática de conteúdo, a partir da leitura exaustiva do material. Dessa forma, identificamos temas e categorias que reportassem os referenciais de gênero, definindo categorias analíticas de interpretação.

\section{Resultados}

De um modo geral, podemos afirmar que o conjunto de sujeitos pesquisados constrói uma multiplicidade de representações acerca do modo como se vive a masculinidade. M esmo da parte deum único sujeito investigado, percebemosuma variedade de compreensões para a possibilidade de ser homem ou ser mulher. Seis categorias sobressaem nos discursos dos entrevistados: trabaIho, corpo, sexualidade, a contraposição à muIher e as tranfformações nas relações de gênero.
0 trabalho como valor moral

para a provisão da família

Para os usuários, o sentido moral que os leva a se afirmarem como sujeitos dignos e de bom caráter funda-se em atitudes e condutas consideradas necessárias para serem reconhecidos como sujeitos detentores de tais valores. Entre tais atitudes, o trabalho assume uma dimensão central, pois permite que os homens "cumpram com suas obrigações". Nesse sentido, o ser identificado como trabalhador confere ao homem uma virtude moral dignificante, afirmando-o peranteos outros, proporcionando-Ihereconhecimento social: "Ser homem idealmente, para começar, é você ter dignidade. Você ser honesto e cumprir com suas obrigações em todo sentido, entendeu?" (Edmundo, 58 anos)

"Eu acho que para ser homem tem queter vergonha na cara, tem que trabalhar, pra você ser honesto e aí ser um homem de verdade". (Raí, 22 anos)

O que parece mover os homenséa percepção deque, por meio do trabalho, eles podem adotar determinadas condutas e atitudes que os impulsionam para o reconhecimento e a respeitabilidade social. Para os entrevistados, o trabalho possibilita as condições necessárias para o cumprimento deseus deveres e obrigações, permitindo, dessa forma, que consigam assumir suas responsabilidades de manter, proteger e cuidar da família, ações diversas vezes reiteradas por eles como sendo inerentes à condição de ser homem.

Com o trabalho, os homens podem assumir o seu papel de provedor da família, reconhecendo-o como uma característica da identidade masculina. Embora os entrevistados não se refiram diretamente ao trabal ho como o motor que viabiliza suas prerrogativas com o espaço doméstico, muitos deles afirmam a importância das responsabilidades com a família e com a manutenção da casa. Desse modo, podemos perceber uma lógica que permite entrelaçar os sentidos dados ao trabalho com os significados de responsabilidade com a sustentação familiar. Em diversos discursos, surgem referências a atributos que colocam os homens como o principal provedor do lar, o chefe de família: "Ser homem é ser o chefe de uma família, ser a pessoa que dirige uma família, que orienta a família. É o chefe da família. 0 homem éaquelequecuida do bem-estar edo futuro da família". (Felix, 51 anos)

Todos somos iguais. M as o homem, por tradição, eu acho que sempre tem que ser o provedor, ser uma pessoa, assim, que sempre tem que está ten- 
tando sempre andar mais pra frente, assim, no dia a dia, pra poder manter os filhos, a mulher. (Giovane, 30 anos)

N esse sentido, a constituição de uma família aparece como um projeto idealizado por vários homens entrevistados. 0 processo de se tornar homem, no sentido de ser reconhecido moral e socialmente, passa necessariamente pelo casamento e pelos filhos. Desse modo, o homem se sente apto e impulsionado a assumir suas responsabilidades sociais. Para isso, é preciso trabalhar, pois só por meio do trabalho o homem consegue se apresentar e fazer valer seu papel de chefe de família: “Um homem pretende casar eter filhos. Aí vêm asresponsabilidades de cuidar delee de quem ele escolheu para viver; e aí vêm osfilhos, que precisam ter o apoio do pai. Desde quando o filho nasce, até onde o filho cresce. $\mathrm{H}$ oje, ser o pai, em relação a ser o masculino, eletem que ter várias responsabilidades que cabe ao homem, numa relação a dois". (Roger, 22 anos)

Todo o processo de construção da identidade masculina associado à categoria trabalho, conferindo ao homem dignidade, respeitabilidade por suas responsabilidades sociais com a família e com a manutenção do espaço doméstico, não deve ser visto separadamente de uma outra dimensão também fortemente atrelada à constituição da imagem do ser homem: o corpo.

\section{O corpo}

Estetema aparecenos significados quea relação entre a estrutura corpórea e a força física dos homens suscita na construção da masculinidade. Referir a capacidadefísica pareceser umaideia quemuitas vezes écompreendida como o fio condutor que potencializa a capacidade de trabalhar: "N a natureza, o ser humano éaqueleque tem mais força física. É aquele quea natureza deu maisforça física e que, normalmente, desde a Antiguidade, por ter essa força física, desenvolveu trabalhosbraçais e, normalmente, na nossa espécie, a obrigação detrazer alimento. E isso, detempo em tempo, veio com o desenvolvimento da sociedade. M esmo não necessitando tanto da força física, até nos dias de hoje muitos homens acham que são obrigatoriamente o poder mais forte dentro de suascasas. M as tudo isso tem uma história". (Denílson, 34 anos)

Com relação ao status que o corpo assume para os homens, vários depoentes trazem as características corporais para salientar seus entendimentos acerca do ser homem. Na maioria das vezes, a alusão não é direta. Algumas vezes, 0 corpo aparece simbolizado por alguma imagem representativa do ser homem no consciente coletivo. Em outros momentos, eles falam do corpo por intermédio de atitudes, capacidades e comportamentos que acham particularmente significativos do ser masculino. Denota-se tal intenção quando atentamos, por exemplo, para a importância dada à estrutura muscular para descrever a força física como algo que qualifica o homem. Outras vezes, simplesmente, a dimensão corporal aparece relacionada ao fato de o indivíduo ser do sexo masculino ou, então, no reconhecimento da presença do órgão sexual masculino naquele sujeito. N os casos de referência ao pênis, observamos que a intenção dos entrevistados não é se autocaracterizar, mas tem a finalidade de reforçar atitudes que outros homens assumem para afirmar sua masculinidade: “Eu acho que ser homem é ser do sexo masculino. Eu não tenho muito uma definição do que é ser homem. Eu acho que tinha aquela definição antiga. A ntigamenteas pessoas diziam: homem éaquele que cuida da casa, aquele que coloca o dinheiro em casa. Homem é aquele que é mais forte, que bate, que não sei o quê. Homem é o que usa a violência pra conseguir as coisas. $\mathrm{H}$ omem é o cabra macho que está sempre... Eu acho que, na minha concepção, ser homem é apenas pertencer ao sexo masculino". (Vanderlei, médico)

"Porque tem muita gente que pensa que é homem porque tem um pinto entre as calças. Pensa que é isso". (Elano, 32 anos)

A possível valorização do homem por meio dos atributos e características que se inscrevem e fazem parte de sua composi ção corporal parece ser um pensamento bastante presente no imaginário da população e essa construção é tida como sendo uma consequência natural e inerente à constituição dos seres humanos.

No nosso estudo, esta questão surge em várias entrevistas. Por exemplo, um usuário toma como referência representações que remetem a características "naturalmente" determinadas e compara os comportamentos humanos com aspectos da vida de outros seres vivos. Ao comentar que o homem tem a necessidade de parecer fortee não transparecer qualquer tipo de problema, o entrevistador o questiona sobre qual seria a razão para o homem ter esse pensamento. Sua resposta segue na direção de que isso seria inerente ao homem: "Eu acho que isso aí é inerente? I nerente ao homem. Eu acho que é uma coisa, assim, como a natureza. $\mathrm{N}$ a natureza também acontece o mesmo. Por exemplo, um macaco... cuida das suas crianças. Não sei... de um elefante. $\mathrm{N}$ a natureza éo mesmo também. $\mathrm{O}$ leão, por 
exemplo, ele cuida da leoa e dos seus filhotes. Procura comida pra eles e não sei o que. Não sei...". (Diego Lugano, 36 anos)

Muitas vezes a referência ao corpo se deu quando falavam de algumas atividades ou características que consideravam apropriadas para designar os homens. Referiam-se, por exemplo, à capacidade de ser ativo, lembrando de situações que remetiam às práticas como o trabalho, a sexualidade, os esportes ou a violência. Isso pode ser percebido no relato de um médico que aponta a dificuldade dos homens em se assumirem com algum problema de saúde e relaciona a prática de atividades físicas como uma característica valorizada por eles: "Eu acho que, por exemplo, a minha geração foi muito criada na atividade, desenvolvendo atividades físicas. Jogava muito futebol. Toda integração quea gente fazia nos grupos envolvia uma atividadefísica. Fazer um esporte, ou então... M esmo nas brincadeiras, né? A coisa do físico, assim, depular muro, desubir, isso éuma característica muito importante pro homem". (Luis Felipe, médico)

\section{Sexualidade}

Uma dimensão importante para a constituição da identidade masculina explorada pelos entrevistados foi a sexualidade. Várias vezes os depoentes mencionaram os significados das práticas sexuais para compor seus modelos de masculinidades, tomando como referência não só as suas próprias vivências, mas também se reportando às representações que compõem o imaginário social acerca dos homens quando se trata dessa questão.

Ao falarem da sexualidade, três aspectos sobressaíram-se nos relatos. Em primeiro lugar, vinculam a identidade masculina a um certo padrão de comportamento sexual, com destaque para a realização de práticas sexuais simultaneamente com várias parcei ras eassociada à ideia de uma vontade sexual impulsiva, o que categorizamos como heterossexualidade impulsiva. Um segundo aspecto diz respeito à rejeição à homossexualidade como um valor identificado com a masculinidade. Por último, associam a masculinidade à capacidade de manter relações sexuais em razão da boa função do órgão sexual, destacando as dificuldades de ereção.

Com relação à heterossexualidade impulsiva, nem todos a reconheciam como o seu principal marco de referência identitária masculina. Preferiam se afirmar, enquanto homens, por meio de outros valores: "Tem muita gente que pensa que pra ser homem tem que ser desse jeito. Porque tem muitas mulheres. Ah, eu tenho xis mulheres. Ainda eles falam: 'Eu dei xis essa noite'. Pensa que ser homem é isso. Para mim é diferente. Tem que ter responsabilidade". (Elano, 32 anos)

À heterossexualidade como referência para a identidade masculina soma-se a repulsão à homossexualidade masculina. Uma grande parcela dos depoentes não considera os homossexuais como homens. Paraum dos depoentes, por exemplo, os homens que se insinuam para outros homens não têm uma atitude de homem. Perguntamos a ele, então, o que seriam essas pessoas: "É metade homem e metade mulher, eu acho. Vamos supor, assim, por exemplo, se um homem chegar e falar. Vamos supor uma brincadeirinha: passar a mão na sua bunda. Já não é uma atitude de homem. É uma atitude errada. Ele fala: 'Ah, estou gostando de você'. Vamos supor, eu sou homem, o homem chega e fala: 'Estou gostando de você'. É uma atitudeerrada isso aí, entendeu? Acho quenão éuma coisa dehomem isso aí, não. Porque eu acho o seguinte, uma pessoa que éhomem mesmo não vai chegar e falar: 'Vou passar a mão na sua bunda, vou pegar no seu...[risos] N o seu bilau, eu vou pegar lá'. 0 que éisso? Eu acho que isso aí não é atitude de homem". (Edmílson, 36 anos)

Ainda com relação às conexões entre masculinidade e sexualidade, merece ser destacada a importância dada por um entrevistado ao significado quea (in)capacidade de ter relações sexuais mobiliza no processo de identificação masculina. 0 entrevistado é um homem diabético com disfunção erétil motivada por complicações da doença e conta como vem lidando com o problema, os sentimentos que rondam ou já passaram por sua cabeça (suicídio) e como estimula outros homens que vivem a mesma situação a enfrentá-la corajosamente. Justifica sua atitude para com outros homens dizendo: "ser homem é não ter vergonha de encarar o que está acontecendo comigo. E para muitos homens, encarar é meio difícil". Para o entrevistado, a impotência é "um problema da masculinidade". Segundo ele, "não é questão de você querer ser macho, questão de você precisar. Você precisa daquilo ali; aquilo ali é a natureza sua. Sexo éuma natureza sua. E vocêfica sem isso, da hora pra outra, isso sobe pra cabeça". (Everaldo, 39 anos)

\section{A mulher e a fragilidade}

Muitas vezes, os entrevistados procuraram tomar a mulher como referência para melhor compreender o ser homem. Uma das questões 
mais apontadas foi uma suposta fragilidade da mulher. Vários depoentes qualificaram as muIheres como mais frágeis que os homens, salientando aspectos de sua fisiologia e de seu corpo para justificar e confirmar sua afirmação. Assinalaram a anatomia do corpo feminino, a menstruação e a gravidez como características que reforçam a ideia de uma maior complexidade da mulher, tornando-a frágil: "A mulher sempreexiste uma gravidez, existeuma coisa eoutra. Tem aqueleprocedimento mensalmente. Tem aquele negócio assi $m$, tal. Vai ter uma criança, tem que haver um pré-natal, tem que fazer uma cesariana. É uma coisa complicada em questão deser mulher". (Edílson, 27 anos)

Para alguns profissionais, no entanto, a fragilidade feminina é algo que se aprende socialmente, sendo parte de um modelo sociocultural introjetado por todos: "Porque elas são educadas para a fragilidade. Em oposição ao homem, que é educado para ser forte. Ela sendo educada para a fragilidade, ela é muito mais sensível às suas mudançasfísicas, aos seus sentimentos eàs suas sensações". (D arci, assistente social)

A ideia de fragilidade nos conduz à questão da sensibilidade como uma referência ao se falar das mulheres. Alguns entrevistados reportaram as mulheres como sujeitos sensíveis, diferentemente dos homens, que seriam mais práticos e objetivos. Tal compreensão leva alguns dos depoentes a questionarem determinadas atitudes das mulheres, pois acham que características como sensibilidade e vaidade dificultam a vivência cotidiana, principalmente quando se trata do trabalho: "Às vezes eu penso que eu gostaria de ser homem. Eu acho que o homem é mais prático com a vida. Ele tem mais foco nas coisas que ele faz. Quando ele tem que resolver uma coisa, ele vai e resolve, não fica com nhénhénhé. Eu não gosto dessa coisa. Eu sou mulher, mas eu sou muito prática. Eu não gosto de nhénhé-nhé. E quando você trabalha com muita mulher, fica muito... É uma fogueira de vaidades. É difícil de trabalhar. A muIher fica olhando a roupa, o sapato, se está gorda, se está magra. Você vêassim: 'Teu cabel o está despenteado. Você tem que alisar o cabelo, não sei o quê'. Perde tempo com coisas que a gente não precisa perder. Então ela fica muito...: 'Ai, meu Deus! Ai, porque hoje eu estou assim'. Ah, não, uff. Vamos trabalhar! Deixa isso pra lá! Agora isso não vai resolver. E o homem é mais direto". (Natália, técnica de enfermagem)

Muitos entrevistados procuraram chamar a atenção para a val orização de aspectos queapontam para a dimensão moral da mulher, citando especificamentea questão do caráter, das responsabilidades e da honestidade. Contudo, o valor moral colocado nesses atributos correspondia a outras condutas e virtudes diferentes daquelas conferidas aos homens. Para os usuários, uma mulher virtuosa não se prostitui e se dedica ao seu homem. Ela deve ser uma boa dona de casa, cuidar de suas responsabilidades domésticas e respeitar o marido: "M ulher? Eu acho queá quase a mesma coisa. É ter caráter, não se prostituir aí, queela pode pegar uma doença aí de qual quer um". (Raí, 22 anos)

“Eu sei lá. É uma coisa quenão explico. Eu tive uma esposa. Ela nunca trabalhou, nunca precisou trabalhar. M inha primeira esposa. Vivia uma vida maravilhosa. Chegava em casa, minha roupa estava tudo prontinho já pro meu banho e tudo. Che gava do trabalho, chegava em casa e estava tudo prontinho. Saía do banho e o jantar já estava na mesa. É uma coisa que eu admiro, entendeu, sobre a mulher". (Carlos Alberto, 41 anos)

\section{As mudanças nas relações de gênero}

M erecem ser destacados os depoimentos que referiram as transformações mais recentes nos modelos de ser homem e de ser mulher, relacionando-as ao processo de mudança em curso na sociedade. Alguns recordaram a maior independência e autonomia das mulheres, apontando 0 crescimento da inserção das mulheres no mercado de trabalho. O utros chegaram mesmo a lembrar do movimento feminista esua contribuição para uma maior participação das mulheres nos processos sociopolíticos cotidianos: “H ojeem dia está muito diferente. Mas, antes, ser homem era ser o provedor, aquelequemanda. Aquelequeexerce a maior influência. Aquele que comanda. $\mathrm{H}$ ojeem dia, esse concei to mudou bastante. Hoje em dia, as mulheres estão mais independentes. M uitasjá trabalham. Lógico que ainda não étotalmentea maioria. M as muitas já se libertaram um pouco desse conceito, um tanto quanto machista, que existia antes. $\mathrm{E}$ os homens acabaram também tomando consciência de que não émais desse jeito. As coisas podem ser divididas". (Fabiana, enfermeira)

O correram, no entanto, questionamentos ao processo de mudança. Alguns homens assinalaram quea maior participação da mulher no mercado de trabalho gerou confusão, pois os papeis eresponsabilidades dehomens e demulheres não ficaram totalmente claros. De certa forma, tais pronunciamentos pareciam uma indagação ou até uma reclamação acerca da perda de espaço dos homens. A impressão era que os homens 
compreendiam as mudanças como uma desorganização da vida em sociedade: "Cada um tem o seu dia a dia. 0 homem cuida das obrigações dele. A mulher tem as obrigações dela. Hoje, como o mundo está mal organizado, as mulheres estão tomando conta quase de tudo. Então, eu acho que a diferença do homem pra mulher éque... A diferença é pouca hoje. Entendeu? Porque tem mulher pilotando avião, tem mulher pilotando metrô, pilotando trem. E tem homem aí que nem sabe varrer uma rua. Entendeu? Então, nessa parte aí, de ser homem e ser mulher, a única coisa que tem diferença de um para o outro, só o sexo mesmo. Porque, parte de serviço, a mulher está quase administrando tudo". (Ronaldo, 45 anos)

Para lidar com essas situações, alguns usuários procuraram argumentos para afirmar a força e o poder da masculinidade. Buscavam a diferença entre homens e mulheres, ressaltando algumas características entendidas como específicas dos homens. Reforçaram, por exemplo, a importância da força física e sua relação com o trabalho, tornando-a símbolo da maior capacidade masculina: "Porque o homem já tem mais capacidade de entrar. Pegar um serviço pesado. Chegar, conversar, esse negócio. Uma coisa diferente da mulher". (Carlos Alberto, 41 anos)

Por fim, éinteressante notar o incômodo que o processo de mudança social de gênero na contemporaneidade provoca em certas pessoas. Nos discursos dealguns profissionais, há menções que problematizam algumas situações vividas pelos homens nos dias atuais. Uns falaram nas exigências, expectativas e confusões que o processo tem gerado em muitos homens, deixando-os por diversas vezes perdidos e atabalhoados. Outros se referiram à inversão de papeis entre homens e mulheres, deixando os homens sem espaço e angustiados. Alguns ainda apontaram para uma frustração e desencanto com certas instituições sociais, como o trabalho e o casamento. Dessa forma, vários profissionais viam os homens como coitados, perdidos, atrapalhados, etc.: "Ser homem é uma coisa complicada hoje em dia. Eles estão meio sem papel na sociedade. A gente está suprimindo cada vez mais a masculinidadedeles, e fazendo cada vez mais o papel deles. Eles estão muito perdidos. Eu, quando converso com eles, elestão meio sem saber aonde ir, o que fazer. Por conta da necessidade da autoafirmação, do machismo, do poder; isso hojeem dia está muito maisnasmulheres do que nos homens. Então eles vêm muito angustiados em relação a relacionamento homemmulher; quando a menina está trabalhando e eles não. Tem muito homem desempregado passando aqui. E ele acaba no bar, bebendo, jogando, arranjando briga. Elesesentemeio diminuído pela esposa. " (Paula, técnica de enfermagem)

\section{Discussão}

Os relatos apontam para a coexistência de uma diversidade de modelos, comportamentos e significados relacionados às masculinidades, articulando os exercícios de masculinidades com esferas dimensionadas cotidianamente na vida social. Discutiremos aqui como, nessa articulação, seus modelos de masculinidades podem trazer repercussões para as práticas de cuidado com a saúde da população masculina.

Um dos primeiros aspectos a ser ressaltado éa relação do trabal ho como a identidade masculina. Ao apontarem que, para os homens se sentirem honrados e reconhecidos como sujeitos sociais, o trabalho assume um papel-chave, os entrevistados colocam o trabalho como constituinte da masculinidade, dado que é confirmado por outros autores ${ }^{14,15}$. Por meio do trabalho, os homens constroem seus modelos de comportamento masculino, definindo uma linha divisória entre o público e o privado ${ }^{14}$. 0 trabalho vale por seu rendimento moral, pela afirmação de sua identidade masculina de homem forte para trabalhar ${ }^{15}$. Dessa forma, os homens são responsáveis por suas famílias como seus provedores principais, assumindo suas responsabilidades éticas de cuidador, enquanto chefe de família ${ }^{16}$. Desse modo, podemos perceber uma lógica que permite entrelaçar os sentidos dados ao trabalho com os significados de responsabilidade com a sustentação familiar.

Para dar conta das suas responsabilidades, 0 homem precisa ser capaz. Parte dessa capacidade está situada em aspectos relacionados à estrutura corporal e é representada pela força física e por determinados atributos que o homem possui. Assim, a experiência corporal tem uma significação na interpretação cultural de gênero, assumindo um papel central para a construção das masculinidades. N os relatos, denotam-se duas questões centrais permeando o processo deidentificação masculina: (1) o determinismo biológico e (2) os significados dos atributos e características percebidas no corpo.

A primeira questão vale-se de um princípio essencializador das características e comportamentos dos homens, em que a posição ocupada por diferentes grupos sociais deriva de limites ou privilégios inscritos na constituição biológica ${ }^{17}$. Tais princípios parecem se repercutir intensamen- 
te na opinião popular, influenciando as ideias acerca de comportamentos e habilidades de homens e de mulheres. Os relatos indicam que é muito mais fácil e confortável a crença em um determinismo natural do que uma construção cultural dos modos deviver em sociedade ${ }^{18}$. Dessa forma, os depoentes parecem seeximir da responsabilidade por comportamentos e atitudes. $\mathrm{N}$ ão questionam a ideologia dominante, nem contestam a forma como o poder se estabelece assimetricamente nas relações sociais.

Apesar disso, não podemos desconsiderar suas concepções. Ao contrário, devemos ficar atentos a esses pontos de vista que permeiam 0 senso comum, pois os mesmos, certamente, servem de argumentos para a compreensão dos processos relacionados às necessidades e cuidados de saúde da população masculina.

A segunda questão - referente aos atributos do corpo, apontando para um ideal centrado na virilidadeena força física - indica quenão é possível ignorar os significados da experiência corporal na interpretação cultural de gênero. Tampouco é possível desconsiderar a importância das construções de gênero nas representações e na forma de se viver e praticar o corpo no cotidiano. Assim, podemos afirmar que a materialidadedos corpos está inserida nos processos de construção de gênero, no sentido de uma incorporação das práticas de gênero ou de uma encarnação social de gênero. N esses processos, os corpos são tanto agentes como objetos dessas práticas, tornando-as práticas reflexivas do corpo ${ }^{19}$.

Quanto à sexualidade, al gumas questões importantes devem ser ressaltadas. A primeira diz respeito à ideia de que a heterossexualidade e a impulsividade sexual seguem sendo um marco para a afirmação masculina, tal como é referido em outros trabalhos ${ }^{20-22}$. No entanto, os relatos apontam para a possibilidade de contestação por parte de alguns homens da sexualidade incontrolável como um modelo a ser seguido por todos. Embora reconheçam a importância do tema, al guns entrevistados tensionam a representação da sexualidade para as masculinidades. Por um lado, reiteram a pertinência do tema mas, por outro, tentam relativizar o seu significado, indicando a existência de questionamentos dos modelos tradicionalmente construídos. Além do mais, por se tratarem de usuários de serviços de saúde com al guma necessidade de saúde, podem se constituir como sujeitos que reelaboram valores e práticas previamente instituídos.

Quanto à homossexualidade, revela-se claramente como a identidade masculina passa por atitudes e gestos que não podem ser identificados com nenhuma imagem homoerótica e como al gumas áreas do corpo devem ser objeto de intensa vigilância, pois representam a vulnerabilidade da própria masculinidade. Tais posicionamentos remetem para outros estudos que discutem a questão da homossexualidade em sua relação com o processo de identidade masculi$n a^{23,24}$. Esses estudos também demonstram que os homossexuais não são considerados homens, problematizando a homossexualidade no contraste com a masculinidade hegemônica. Ou seja, a desqualificação dos homossexuais nas interpretações do que vem a ser homem parece ser algo necessário ao processo de afirmação da masculinidade, indicando que a homossexualidade masculina desempenha um papel-chavena regulação da conduta masculina normativa ${ }^{24}$.

A questão da potência sexual merece destaque pelos sentidos colocados para a garantia da masculinidade, constituindo um fundamento nuclear no processo de identificação de gênero. Conforme outros autores ${ }^{25}$, essas características contribuem para que o homem se reconheça como sexualmente ativo, simbolizando sua virilidade e autoafirmação.

As interpretações acerca da identidade feminina, com enfoque na fragilidade e sensibilidade da mulher, remetem às perspectivas de gênero ideologicamente consagradas como tradicionais e essencialistas. Ora as mulheres são culturalmente valorizadas (como mãe eesposa), ora elas são desqual ificadas socialmente ( por serem pouco práticas e objetivas). N esse sentido, os nossos entrevistados afirmam uma visão estereotipada da mulher, partindo de uma ótica da diferença dos papeis sociais influenciada pela visão naturalizada do que vem a ser homem e mulher.

Para os depoentes, um ideal feminino estaria centrado, por um lado, em comportamentos e posturas relacionadas ao recato e ao pudor e, por outro lado, ao desempenho na manutenção do espaço familiar. Para os homens, ao contrário, valorizam-se aspectos que remontam à sua responsabilidade no sustento e provisão do lar. Assim, percebemos a construção de um modelo derelações de gênero bastante tradicional, cristalizado numa divisão sexual do trabal ho e do poder nas relações afetivo-sexuais. As mulheres estariam submetidas e subordinadas aos homens, restritas ao ambiente privado, o qual deveriam honrosamente respeitar de forma responsável.

Entretanto, os discursos também pontuam as mudanças nas relações sociais de gênero. Para muitos entrevistados, as transformações ocorri- 
dasna sociedade ocidental mais recentementetrazem dilemase conflitos à socialização doshomens, o queal guns autores denominam vitimização dos homens ${ }^{26}$. Tais indivíduos estariam vivenciando expectativas que confrontam os ideais hegemônicos de masculinidade com a prescrição de um modelo que limita comportamentos considerados legítimos para a identidade masculina, ge rando um sentimento de insegurança.

Essa discussão remete à polêmica da existência ou não de uma crise da masculinidade ${ }^{17,18}$, fato que tem suscitado grandes debates, levando-nos a perceber que as prerrogativas atuais sobre o ser homem mobilizam diferentes parcelas da sociedade. No entanto, não podemos considerar esses relatos como sendo apenas uma postura vitimizadora dos homens ou, então, algo que respalda uma hierarquia que valoriza a dominação masculina. Ao contrário, devemos re conhecer nesses depoimentos aspectos das iden- tidades em conflito, sugerindo possível momento histórico de reconstrução do próprio modelo hegemônico. Ou seja, um modelo que precisa ser superado, sem ainda uma definição clara do que será no futuro.

Concluindo, percebemos que as diferentes dimensões discutidas pelos entrevistados devem ser questões consideradas na perspectiva de gênero nas ações de atenção primária. 0 modo como tais questões são interpretadas nos depoimentos podem representar impactos para a saúdemasculina. N esse sentido, temáticas como trabalho esexualidade, por exemplo, devem ser contempladas nas discussões de prevenção e promoção da saúde, desde um ponto de vista que permita ampliar o campo de percepção das relações entre gênero e saúde. Com isso, se pode alcançar uma maior problematização de tais temas, com também enfrentar as iniquidades de saúde e de gênero.

\section{Colaboradores}

WS Figueiredo eLB Schraiber participaram igualmente de todas as etapas da elaboração do artigo. 


\section{Referências}

1. Courtenay WH. Construction of Masculinity and Their Influence on Men's Well-Being: A Theory of Gender and Health. Soc Sci M ed 2000; 50(10):13851401.

2. Laurenti R, Mello-Jorge MHP, Gotlieb SLD. Perfil epidemiológico da morbimortalidade masculina. Cien Saude Colet 2005; 10(2):35-46.

3. Schraiber LB, Gomes R, Couto MT. Homens e saúde na pauta da saúde coletiva. Cien Saude Colet 2005; 10(2):7-17.

4. Schofield T, Connell RW, Walker L, Wood JF, Butland DL. Understanding M en's Health and IIIness: A Gender Relations Approach to Policy, Research, and Practice. J Am Col Health 2000; 48(6):247-256.

5. Keijzer B. Hasta Donde el Cuerpo Aguante: Género, Cuerpo y Salud Masculina. In: Caceres CF, Cueto $M$, Ramos M, Vallens S, compiladores. La Salud como Derecho Ciudadano: Perspectiva y Propuestas desde América Latina. Lima: Universidad Peruana Cayetano Herida; 2003. p. 137-152.

6. Figueiredo WS. Assistência á saúde dos homens: um desafio para os serviços de atenção primária. Cien Saude Colet 2005; 10(1):105-109.

7. Pinheiro RS, Viacava F, Travassos C, Brito AS. Gênero, morbidade, acesso e utilização de serviços de saúde no Brasil. Cien Saude Colet 2002; 7(4):687-707.

8. D'Oliveira AFPL, Schraiber LB. Violência de gêne ro, saúde reprodutiva e serviços. In: Giffin K, Costa SH, organizadores. Q uestões da saúde reprodutiva. Rio de Janeiro: Fiocruz; 1999.

9. Schraiber LB. Equidade de Gênero e Saúde: o cotidiano das práticas no Programa de Saúde da Família do Recife. In: Villela W, Monteiro S, organizadores. Gênero e saúde: Programa Saúde da Família em questão. Rio de Janeiro: Abrasco/U NFPA; 2005. p. 39-61.

10. Scott J. Gênero: uma categoria útil para a análise histórica. Recife: SOS Corpo; 1995.

11. Connell RW. Masculinities: knowledge, power and social change. Los Angeles: University of California Press; 1995

12. Aquino EM L. Gênero e saúde: perfil e tendências da produção científica no Brasil. Rev. Saude Publica 2006; 40(N Esp.):121-132.

13. Figueiredo WS. M asculinidades e Cuidado: diversidade e necessidades de saúde dos homens na atenção primária [tese]. São Paulo (SP): Faculdade de Me dicina, Universidade de São Paulo; 2008.

14. Nolasco S. 0 mito da masculinidade. $2^{a}$ ed. Rio de Janeiro: Rocco; 1995.

15. Sarti CA. A família como espelho: um estudo sobre a moral dos pobres. 3a ed. São Paulo: Cortez; 2005.

16. Valdés T, Olavarría J, compiladores. Masculinidades y Equidad de Género en América Latina. Santiago: FLACSO; 1998.
17. Citelli MT. Fazendo diferenças: teorias sobre gênero, corpo e comportamento. Revista Estudos Feministas 2001; 9(1):131-145.

18. Schraiber LB, D'Oliveira AFPL, Falcão MTC, Figueiredo WS. Violência dói e não é direito: a violência contra a mulher, a saúde e os direitos humanos. São Paulo: Editora UNESP; 2005

19. Connell RW. El imperialismo y el cuerpo de los hombres. In: Valdés T, Olavarría J. compiladores. $M$ asculinidades y equidad de género en América Latina. Santiago: FLACSO; 1998. p. 76-89.

20. Salem T. “Homem... já viu, né?": representações sobre sexualidade e gênero entre homens de classe popular. In: Heilborn ML, organizador. Família e sexualidade. Rio de Janeiro: Editora FGV; 2004. p. 15-61.

21. Gomes R. Sexualidade masculina e saúde do homem: proposta para uma discussão. Cien Saude Colet 2003; 8(3):825-829.

22. Olavarría J. Desejo, prazer e poder: questões em torno da masculinidade heterossexual. In: Barbosa RM, Parker R, organizadores. Sexualidades pelo avesSo: direitos, identidades e poder. Rio de Janeiro: IMS/ UERJ; São Paulo: Editora 34; 1999. p. 153-174.

23. Da Matta R. Tem pente aí?: reflexões sobre a identidade masculina. In: Caldas D, organizador. Homens. São Paulo: Editora SENAC; 1997. p. 31-49.

24. Parker R. Hacia una economía política del cuerpo: construcción de la masculinidad y la homosexualidad masculina en Brasil. In: Valdés T, Olavarría J, compiladores. M asculinidades y Equidad de Género en América Latina. Santiago: FLACSO; 1998. p. 106127.

25. Leal OF, Boff AM. Insultos, queixas, sedução e sexualidade: fragmentos de identidade masculina em uma perspectiva relacional. In: Parker R, Barbosa $R$, organizadores. Sexualidades brasileiras. Rio de Janeiro: Relume Dumará/ABIA/IM S-UERJ; 1996. p. 119-135.

26. Oliveira PP. A construção social da masculinidade. Belo Horizonte: Editora UFM G; Rio de Janeiro: IUPERJ; 2004.

Artigo apresentado em 13/05/2008

A provado em 31/10/2008

Versão final apresentada em 30/11/2008 